\title{
High-dose influenza vaccination
}

\author{
Daniel Dalcin MD, Jeffrey C. Kwong MD MSc
}

Cite as: CMAJ 2019 March 18;191:E313. doi: 10.1503/cmaj.181477

CMAJ Podcasts: author interview at https://soundcloud.com/cmajpodcasts/181477-five

\section{High-dose influenza vaccine contains 4 times the amount of 1 antigen of standard-dose vaccines}

High-dose trivalent inactivated influenza vaccine (HD-TIV) contains $60 \mu \mathrm{g}$ of hemagglutinin per strain, whereas standard-dose vaccines (SD-TIV) contain $15 \mu \mathrm{g}$. Given the burden of influenza A subtype H3N2 in older adults and evidence of better efficacy of HD-TIV relative to SDTIV (Box 1), ${ }^{1-4}$ Canada's National Advisory Committee on Immunization recommends HD-TIV over SD-TIV for adults aged 65 years and older; however, the comparative effectiveness of HD-TIV over other options (MF59-adjuvanted TIV or standard-dose quadrivalent influenza vaccine) is uncertain. ${ }^{5}$ The HD-TIV is publicly funded for adults aged 65 and older in Ontario and for long-term care residents aged 65 and older in Saskatchewan, Manitoba and Prince Edward Island.

2 In older adults, HD-TIV is more efficacious than SD-TIV

A clinical trial involving 31989 adults 65 years of age and older found that HD-TIV was $24 \%$ ( $95 \%$ confidence interval [CI] $10 \%$ to $37 \%$ ) more efficacious than SD-TIV in preventing laboratory-confirmed influenza, with $23 \%$ higher efficacy $(95 \% \mathrm{Cl} 6 \%$ to $38 \%)$ against influenza A subtype H3N2. ${ }^{1}$ Influenza A subtype H3N2 accounts for most severe illnesses among older adults. To prevent 1 additional case of influenza, 200 individuals need to receive HD-TIV instead of SD-TIV. ${ }^{1}$

\section{3}

HD-TIV is associated with reduced hospital admissions and emergency department visits in older adults

A cohort study including adults 65 years and older found that those who had received HD-TIV $(n=929730)$ had a $22 \%(95 \% \mathrm{Cl} 16 \%$ to $27 \%)$ reduction in influenza-coded hospital admissions and emergency department visits compared with those who received SD-TIV $(n=1615545){ }^{2}$

\section{4 \\ HD-TIV is associated with reduced post-influenza deaths among older adults}

A cohort study including 2722909 adults aged 65 years and older found that HD-TIV was associated with a $36 \%$ (95\% CI 9\% to 56\%) reduction in post-influenza deaths compared with SD-TIV during the 2012/13 season, but no reduction during the 2013/14 season. ${ }^{3}$

\section{Mild adverse events occur more often with HD-TIV than with SD-TIV}

Short-term data from clinical trials showed higher rates of mild systemic reactions (e.g., fever) among individuals receiving HD-TIV than among those receiving SD-TIV (relative risk $1.2,95 \% \mathrm{Cl} 1.1$ to 1.3 ), but not serious adverse events (relative risk $0.92 ; 95 \% \mathrm{Cl} 0.85$ to 0.99 ). ${ }^{1,4}$

\section{Box 1: Absolute outcome comparisons among adults aged 65 years and older receiving SD-TIV and HD-TIV

\begin{tabular}{|lcc|}
\hline Outcome & SD-TIV & HD-TIV \\
\hline $\begin{array}{l}\text { Laboratory-confirmed } \\
\text { influenza }^{1}\end{array}$ & $1.9 \%$ & $1.4 \%$ \\
\hline $\begin{array}{l}\text { Hospital admissions } \\
\text { for laboratory- } \\
\text { confirmed influenza }\end{array}$ & $\begin{array}{c}1.10 \text { per } 10000 \\
\text { person-weeks }\end{array}$ & $\begin{array}{c}0.86 \text { per } 10000 \\
\text { person-weeks }\end{array}$ \\
\hline $\begin{array}{l}\text { Post-influenza death } \\
\text { p }\end{array}$ & $\begin{array}{c}\text { 0.038 per 10000 } \\
\text { person-weeks }\end{array}$ & $\begin{array}{c}0.028 \text { per } 10000 \\
\text { person-weeks }\end{array}$ \\
\hline Mild adverse events $^{* 4}$ & $29.4 \%$ & $34.3 \%$
\end{tabular}

Note: HD-TIV = high-dose trivalent inactivated influenza vaccine, SD-TIV = standard-dose trivalent inactivated influenza vaccine. *For example, fever, headache, malaise and myalgia.

\section{References}

1. DiazGranados CA, Dunning AJ, Kimmel M, et al. Efficacy of highdose versus standard-dose influenza vaccine in older adults. N Engl J Med 2014;371:635-45.

2. Izurieta HS, Thadani N, Shay DK, et al. Comparative effectiveness of high-dose versus standard-dose influenza vaccines in US residents aged 65 years and older from 2012 to 2013 using Medicare data: a retrospective cohort analysis [published correction appears in Lancet Infect Dis 2015;15:263]. Lancet Infect Dis 2015;15:293-300.

3. Shay DK, Chillarige Y, Kelman J, et al. Comparative effectiveness of high-dose versus standard-dose influenza vaccines among US Medicare beneficiaries in preventing post-influenza deaths during 2012-2013 and 2013-2014. J Infect Dis 2017;215:510-7.

4. Falsey AR, Treanor JJ, Tornieporth N, et al. Randomized, doubleblind controlled phase 3 trial comparing the immunogenicity of high-dose and standard-dose influenza vaccine in adults 65 years of age and older. J Infect Dis 2009;200:172-80.

5. Canadian immunization guide chapter on influenza and statement on seasonal influenza vaccine for 2018-2019. An Advisory Committee Statement (ACS). National Advisory Committee on Immunization (NACI). Ottawa: Public Health Agency of Canada; 2018. Available: www.canada.ca/en/public-health/services/publications/healthy -living/canadian-immunization-guide-statement-seasonal-influenza -vaccine-2018-2019.html\#2.6 (accessed 2019 Mar. 1).

\section{Competing interests: None declared.}

This article has been peer reviewed.

Affiliations: Faculty of Medicine (Dalcin), Dalhousie University, Halifax, NS; ICES (Kwong); Public Health Ontario (Kwong); Department of Family and Community Medicine (Kwong), University of Toronto, Toronto, Ont.

Correspondence to: Daniel Dalcin, ddalcin@nosm.ca 